\title{
Fostering Quality Teachers in Teacher Education in the Context of Internationalization: Tasks Ahead
}

\author{
Prakash Chandra Jena ${ }^{1 *}$, Rashmi Ranjan Biswal ${ }^{2}$ \\ ${ }^{1}$ School of Education, Lovely Professional University, Punjab, India \\ ${ }^{2}$ Research Scholar, Ravenshaw University, Odisha, India \\ *Email address: drpcjena@gmail.com
}

\begin{abstract}
Education being a process of strengthening human resources, its quality assumes special significance within the larger framework of personal, social and national development. The educational system of the 21 st century must be oriented toward creating conditions that allow school students to act and learn freely in productive collaboration with their teachers, and also with their parents and other members of their community, local and global. Government of India's Ministry of Education in its report said "the most important factor in the contemplated educational reconstruction is the teacher, his personal qualities, educational qualifications, professional training and his place in school and community. Although, India is developing democratic country, to bring qualities in all aspects of teacher education in the light of internationalization, matter of serious concerned and needs immediate attention so that we may get such teachers who not only will possess world class knowledge but also right attitude to work and live with open mindedness.
\end{abstract}

Keyword: Teacher Education; Internationalization

\section{INTRODUCTION}

The transformation of society into a 'learning society' where relevant education is assessable to each and every member, is the responsibility of teachers and consequently that of teacher educators and hence of teacher education system. In recent decades, the system of teacher education has grown manifold but has been under serious criterion for being static and unresponsive to bring a change in the school and overall social system. There is also a feeling that teacher education is not effective in turning out efficient teachers and this concern is adequately reflected in the National Policy of Education (NPE, 1986) and Programme of Action (1992). It calls for complete overhaul of the system. It has been rightly said that the destiny of a country is shaped in her classrooms. Question arises as to who are the educators and how the education will be imparted. It has been aptly remarked "As is the teacher, so is the school, as is the school, so is the nation". A teacher prepares the future citizens and builds a whole nation. He is one of the principal pillar on which the edifice of the nation's educational system rests. If the system lacks good teachers, the education system will fail.

Twenty first century is knowledge society, a globally linked one, borderless to yield reciprocal benefits for all nations. Higher education is the fundamental necessity in this society. This highly interdependent world, requires a higher education system where internationalization promotes cultural diversity and fosters intercultural understanding, 
respect, and tolerance among people. Such internationalization of higher education contributes to building more than economically competitive and politically powerful regional blocks; it represents a commitment to international solidarity, human security and helps to build a climate of global peace. According to Powell (2001) international education prepares our citizens to live, work and compete in the global economy and promotes tolerance and reduction of conflict. But there is unevenness in the movement of students. In academic year 2005/06, there were 76,503 students from India studying in the United States and only 1767 US students have taken part in short-term study abroad in India. If India is the largest democracy in the world and the US is the one of the more important democracy in the world then why is the movement of students so uneven (Rhodes,2002). India must also catch up pace in internationalization of higher education in the present scenario due to following reasons:

It would lead to improvement in quality of higher education through partnership and networking.

$>$ It will broaden the mental sphere of the students. They will understand the dynamics of different global systems, exposure to people, languages, and culture.

Promote Indian culture abroad.

Induce international understanding.

Yield rich financial harvests.

\section{The National Council of Teacher Education (NCTE) has identified the following ten competencies in teachers.}

$>$ Contextual competencies.

$>$ Conceptual competencies.

$>$ Curricular and content competencies.

$>$ Transactional competencies.

$>$ Competencies in other educational activities.

$>$ Competencies related to the preparation of teaching learning materials.

Evaluation competencies..

Management competencies.

Competencies related to Parental contact and co-operation.

Competencies related to community contact and co-operation.

The concept of Internationalization of teacher education is not a new phenomenon. It is only a replica of nature's entelechy called continuum. Our Holy Rigveda (1.81.1) enunciates : Aa nou Bhadra: Katvo Yantu Vishwata i.e. Let Noble Thoughts Come To Us For Ever From Every Side. Teaching and learning are two sides of the same coin. But present day teacher stands poles apart and is described by various names such as a teller, an information giver, a facilitator, a learning manager and a knowledge worker i.e. a professional like any other professional namely an engineer, a doctor, a lawyer, a bank manager who receives cash payment for the services he renders. His job is not to shape the humanistic destiny but the mundane economy of his pupils. The tools which present teacher employs are not of meditational or transcendental nature but material gadgets which are constantly undergoing changes e.g. from black board and white chalk to green board and coloured chalk. And now his tools are computers, lap tops, projectors and laser lights. The resources at his disposal are many and variegated. So much so that he is going increasingly into the background with gadgets in the fore front. His timings are fixed, salaries are constantly revised, curriculum ever changing and expanding. He has absolutely no control over the content he is going to teach because that has been fixed by the universities and other agencies. While he does not 
have the competence and proprium to open his third eye but he definitely has the liberty to change his gadgets enriching him with the potential of sharing and knowing what ever is happening around the world with the click of the mouse. His knowledge is becoming increasingly pinpointed and focused in the world of super specializations. The positive aspect of the present day teacher is that his job has become fully professional. The policy makers of the present day education have understood and realized the ground reality that teaching is no longer a fetish. Content is researched by one, devised by the second, designed by the third, experimented by the fourth, delivered by the fifth, examined by the sixth, evaluated by the seventh, rated by the eighth and patented by the ninth, advertised by the tenth and marketed by the eleventh and so on. In all the above mentioned areas thoroughly professional approaches are being adopted. And now with the dawn of ODL techniques, concept of autonomous learner has already become a reality adding a new dimension to the already expanding contours of teacher preparation. So the task of preparation of teachers has already become highly intricate and variegated. With the help of $\mathrm{E}$ learning and $\mathrm{M}$ learning devices, every place right from the bed room to any room, play ground to moving train of flying plane, he can teach and learn.

These two diametrically opposed phenomena have given birth to a major cultural lag i.e. how to cope up with the gargantuan task of preparation of teachers for higher education of the International standards. It is in this context that our policy makers have to devise new and newer strategies for developing and preparing our present as well as prospective teachers for higher learning. But before any preoperational strategies are devised with an eye of international standards, some factors need close examination. To begin with, development of authentic content material is the first area. No doubt, flood of material is already available with us through internet but who will certify its authenticity? Who will bear the responsibility that the facts available on the net are true and verified?

Secondly, the content material has to be translated into other languages as societies are becoming more and more multi-lingual and poly-lingual. Yes, English language is an International asset yet the fact remains that mother tongue is the most suitable and natural way of teaching and learning programmes.

Thirdly, nations are becoming increasingly multicultural. The content developed at the National level must find its cultural equivalents easily identifiable both by the teachers and the learners.

Fourthly, the content material has to be developed for different levels i.e. higher, advanced and super advanced level with ample scope for further research. I have drawn these distinctions deliberately because there are greater divides which exist not only among plural ethnicities among different states of one nation but also different nations across the globe.

In view of the above, preparation strategies in respect of teacher education have to be modified with vigorous zeal to cope up with the fast changing educational scenario. To begin with, each training institute of teachers must have the following centres on scientific basis under the broad banner of human resource management:

- Research Centre

- Recruitment Centre

- Training and Development Centre

- Supervisory and Directional Centre

- Performance and appraisal Centre.

- Idea bank and Idea Capital what Japanese call kaison. 


\section{PREPARATION OF TEACHERS IN THE CONTEXT OF INTERNATIONALIZATION}

- First of all teacher should understand his role in learning process. He should work as a facilitator not as a boss.

- Teacher should be receptive to concurrent international trends and systems, assimilate knowledge gathered from all sources and disseminate it in a relevant form according to the requirements of his/her pupils.

- The present day teacher should be expert in student centred learning (SCL). It is only possible when teacher will be expert in understanding child psychology and learning process.

- Teacher should have continuous thirst for technology because their students are technology saturated.

- Today's teacher should be highly dynamic. The society is full of disparities, so recognizing needs of the hour and fulfilling them is a tough job.

- Due to international mobility and increased population of our country, teacher should be well - versed about the techniques of Mass Education, such as distance education, networking partnership, cooperative partnership by commonwealth countries (Pooling resources and expertise of some open universities).

- Twin partnership in formal education (Sharing campus facilities between two countries.)

- Teaching skills should be competency based and not knowledge based. Today's teacher is not only disseminator of knowledge because easy access of knowledge through information technology is available enough, but the teacher has to work as guide, who will initiate the right direction of getting knowledge and help in assimilation of it.

- Teacher should be expert in original thinking and in generating his own knowledge because he has to give to his/her students something better than they get from internet.

- Teacher of higher education should be bilingual i.e., he should be expert in English as well as in his national language. English has its importance in the form of international language and language of communication. He/she should not be prejudicial about English as language of British rulers but should take it as a tool for internationalization of education.

- At the time of teaching preparation, orientation and refresher courses should be compulsory for updation of faculty from time to time. The faculty of Academic Staff Colleges should be exchanged between countries which will give our teachers an international view point about learning.

- Teacher of higher education has to deal with youth of our country who are the centers of our progress and revelation. Teacher should not be of orthodox and stereo-type mind-set because he/she has to deal with mentally liberated youth of de-colonized brain.

- Teacher should take technologies as his helping hand - not as his substitutes. They should create expertise in educational technologies in both ways, technology in education and technology of education.

\section{INTERNATIONALIZATION OF THE CURRICULA IN THE CONTEXT OF INTERNATIONALIZATION}

Curricula should be dynamic and flexible so that it can provide understanding in global context as well as adaptation according to local needs. An OECD study has provided the following definition of internationalized curricula:"Curricula with an international orientation in content, aimed at preparing students for performing professionally and socially in an 
international and multi-cultural context, and designed for domestic students as well as foreign students".

- Curriculum should contain emerging trends of society in national and international reference.

- It should contain new knowledge and new perspectives and full use of human resources of universities.

- Curriculum should have enhanced quality in terms of professional skills, strengthening of foreign language learning, expansion of the range of courses, inter-cultural communication skills.

- Some aspects such as philosophy, psychology and technology should be added as core curriculum of teacher education in every country and methodology and techniques of teaching should be need based and activity based.

- Updating of curriculum should be done periodically at international level.

Since learning is a lifelong process, teaching too falls in the same category. Twice a year a teacher must undergo orientation and refresher courses but certainly not like the ones we have in the present day scenario, where there are mere talkers and sheer listeners.

A teacher must be asked to prepare a relational model of his content. No doubt, theory is important but more important is applications in real life situations.

$>$ Expert agencies should be created by the administration to evaluate the work of a teacher vis-à-vis its impact on students. Since we have already become a global nation and we are heading towards developing a cosmic width, multi cultural programmes in all fields should be incorporated in area of study. Culture barriers create taboos and walls and those blocks can be dissolved when the invisible understanding and unity among the seemingly different looking cultures is seen and felt through proper exposure.

$>$ Since higher learning involves higher issues aiming at enrichment of mankind, there should be a free flow of teacher traffic from one institution to the other. The best teacher in one area can always be declared a National teacher. Although, we too have National Professors but by the time they achieve the status, their physical strength begins to block their way. What I mean is, increasing significance should be given to the creation of consortia not only of institutions but also among teachers.

The controlling agencies must ensure that such teachers who are declared National assets are free from economic worries and their families receive adequate support from the institution which they serve. This concept is akin to our age long traditions when feeding the monks was the responsibility of the society. Yes, inconvenience of physical dislocation comes in the way but with plethora of information technologies at our command, easy assess to $\mathrm{E}$ learning and mobile learning should be encouraged by adopting distributed classroom strategies through broad band, Video conferencing inter netting, online strategies. E-teaching, E-lecturing, E-mentoring, E-tutoring, E-peer interaction and so on. But these strategies are only support systems. There is no substitute to the human teachers who have the potential to exude placid and serene waves.

\section{CONCLUSION}

Last but not least, each training institute must have an Idea Bank to build an Idea Capital for updated research and long term plans. What was true in the past may not be true in the present, what was acceptable in the past may not be so in the present, what was practiced in the past times may not be practicable in the present times but we must realize every age has its on truths and priorities but universal truth should always be a universal priority for all times and for this reason we seek your permission to close my paper with a shaloka: 
Guru Brahma, Gurur Vishnu, Gururdev Maheshwra, Gurur Sakshaat Parbraham, Tasmay Shri Guruve Namah

The truth contained in this famous transcendental Shaloka is certainly not that Guru has the status of Brahma, Vishnu or Mahesha but Guru has the responsibility of teaching Brahma's message of creating something new through knowledge (Saraswati), Vishnu's love for nurturing and preservation of what is good through Laxmi and Mahesha's will for destruction of what is unwanted through Shakti (Parwati). Therefore with knowledge, money and power of decision making, preparation of teachers must focus on the processes of learning what is new, relearning what is worth and unlearning what is redundant and this cycle should go on an on for Preparation of teachers with International standards and cosmic vision.

\section{References}

[1] Dutt, A. K. (2005). Higher Education in the $21^{\text {st }}$ century: Challenges and Opportunities; New Delhi: University News, Vol. 43, No. 48.

[2] UNESCO (1998). Higher Education in the $21^{\text {st }}$ century: Vision and Action, The Final report of the World Conference on Higher Education. Paris UNESCO.

[3] Xavier, Alphonso, S.J. (2006). Community College System: Empowerment Endorsed; University News, Vol. 44, No. 13, PP.6-8

[4] Corwin, R.G.(1973). Organizational Reform and Organizational Survival: The Teacher Corps as an Instrument of Educational Change, New York; Wiley

[5] Darling-Hammond, L. and Sclan, E.M.(1996). Who teaches and why: Dilemma of building a profession for twenty-first century schools. In J. Sikula (Ed.) Handbook of Research on Teacher Education. Second Edition. Pp.67-101. New York: Macmillan.

[6] Power K.B. and Panda S.K. (1995). Higher Education in India-In Search of Quality, Association of Indian Universities, New Delhi.

[7] Higher Education Quality Assurance Framework 00/G (2000).

[8] Kaur, Kuldip. (2003). Planning higher education. Higher Education in India (17812003). University Grants Commission, New Delhi and Centre for research in Rural and Industrial Development (CRRID), Chandigarh.

[9] Sudha Rao, K. (2002). Educational policies in India. Analysis and Review of promise and performance. National Institute of Educational Planning and Administration, New Delhi, pp.1-114.

[10] Jennifer Rowley, (2000). Is Higher Education ready for knowledge Management, The International Journal of Education Management, 14/7, pp 325-333.

[11] Jilinda J. Kidwell, Karen M, Vander Linde and Sandra L Johnson, (2000). Applying Corporate Knowledge Management Practices in Higher Education, Educause Quarterly, pp 28-33. 